\title{
Clinical trial for Fabry disease faces continuing hurdles
}

Published at www.cmaj.ca on Oct. 6

A controversial clinical trial of two expensive treatments for Fabry disease is facing yet another hurdle, this time because of the worldwide shortage of one of the enzyme replacement therapies.

Earlier, the federal government's decision not to renew its contribution to the Canadian Fabry Disease Initiative trial past Sept. 30 sent other contributors scrambling to find ways to extend the 10-year trial past the initial threeyear funding agreement. (CMAJ 2009 ;181:365-6)

Negotiations among those other contributors - the provinces and the two biotechnology companies - are continuing, according to the province if Ontario, which is leading the negotiations.

The trial. which involves a head-tohead comparison of agalsidase beta (Fabrazyme) and agasidase alfa (Replegal), is the vehicle through which Canadian Fabry patients now receive the approximately $\$ 300$ 000-a-year therapy.

But the international shortage of agalsidase beta has created new challenges. Patients such as Darren Bidulka, the new president of the Canadian Fabry Association, have been getting half the regular dose of agalsidase beta for the past two months.

"I've had four doses reduced to half - I usually get $70 \mathrm{mg}$ every two weeks and have been getting $35 \mathrm{mg}$ and I'm concerned there could be more reductions," says Bidulka. He says he hasn't experienced a noticeable difference in his health, but reports that other patients say they have. Fabry disease is a rare, inherited enzyme deficiency which can cause heart, kidney and nerve tissue damage.

The trial's principal investigator, Dr. Michael West of Halifax, Nova Scotia, says the shortage of agalsidase beta is causing him to lose sleep because of concern for patients and the possible risks posed to the integrity of the postmarket trial. (As well as providing ther- apy to Canadians, the trial is designed to assess the relative usefulness of agalsidase beta and agalsidase alfa, both of which have been approved for marketing by Health Canada).

In late September, agalsidase beta manufacturer Genzyme announced that the shortage, first flagged in June and caused because of viral contamination of its bioreactors, would continue until the end of 2009.

Nova Scotia, Alberta, Ontario and British Columbia formally notified the Canadian Fabry Association that they will continue to pay for patients' treatment expenses past the Sept. 30 deadline. Nova Scotia, which has the highest incidence of Fabry disease in Canada, hiked its budget for supporting them to $\$ 4.9$ million in 2009-10 from $\$ 3.3$ million in the previous fiscal year.

The trial was established "to collect clinical information to further evaluate treatment and get a better understanding of the therapy," Bob Nakagawa, assistant deputy minister for pharmaceutical services in British Columbia, stated in a letter to the association.

"This national initiative also allowed governments to pool their resources to support the high cost of treatment and ensure ongoing access to treatment across the country. . . . While BC is disappointed at the federal government's decision to disengage from the study, BC will continue to work of the Canadian Fabry Disease research study."

The unusual nature of the trial has been a source of frustration for Fabry patients and for the physicianinvestigators. For example, West says the investigators have been unable to amend the trial protocol to align it with current clinical guidelines for patient eligibility because of an "extremely cumbersome process."

"Our number one goal is that patients who will benefit from the therapy will get it," he says.

But proposals to amend the trial protocol have to be approved by all provinces and the two biotechnology

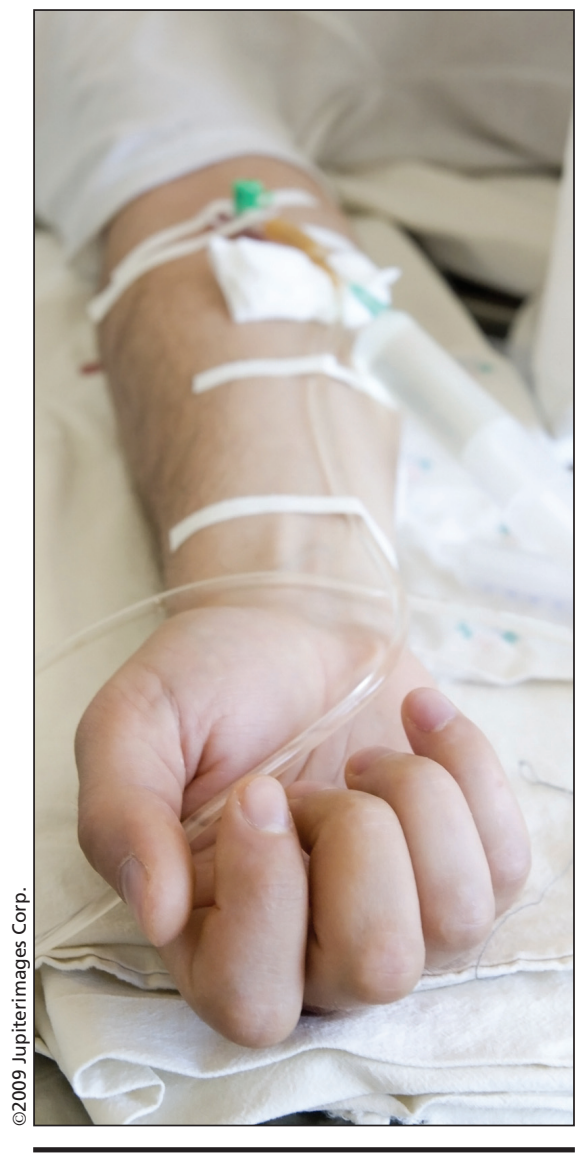

Enzyme replacement therapy for people with Fabry disease costs as much as $\$ 300000$ a year.

companies, and subsequently by the research ethics boards at the nine study sites, he says. The investigators have recommended that a management committee be established to streamline the amendment process.

The trial also lacks a clear sponsor. The scientific oversight committee for the trial, convened by the Canadian Institutes of Health Research, had recommended that CIHR become the trial sponsor, but it declined on the basis that it is not a funder and hence "does not exercise any control over the study."

Durhane Wong-Reiger, president of the Canadian Organization for Rare Diseases, says the trial is "badly conceived" and the fact that the provinces 
will continue to fund therapy through the trial is "a huge disappointment." Instead, Canada should develop a national policy for funding treatment for rare diseases, and provinces should fund the therapy outside of the trial context, she argues.

But West says the high annual cost of the enzyme replacement therapy means that, even without the trial, provinces would want to conduct post- market surveillance and would have to pay for data collection in order to monitor safety and outcomes.

Provinces “wouldn't want to spend the money without knowing what is happening. ... If the drug only cost pennies, it would be just a safety issue, but with the price tag, the question of cost effectiveness comes up."

It will likely be two more years before the trial has enrolled enough patients to be properly powered, West says, but preliminary data shows no detectable difference between the two forms of enzyme replacement therapy.

A spokesperson says CIHR would agree to play a scientific oversight role if the project is extended, but said it is "too early to speculate on the future of the study." — Ann Silversides, CMAJ

DOI:10.1503/cmaj.109-3071 